\title{
A new subspecies of Chrysochroa margotana Novak, 1992 (Coleoptera, Buprestidae) from Myanmar
}

\author{
A.S. Zubov, A.Yu. Titarenko \\ Bolotnikovskaya6B,ap.103,117556 Moscow,Russia,Email:riprulez@mail.ru \\ Publicly Traded Company "Morpho Absoloni" \\ Email:odindva3@gmail.com
}

The paper provides the description of a new subspecies of Chrysochroa margotana Novak, 1992 from Burma and restoration of C. margotana Novak, 1992 as a valid specie name as a result of morphological analysis of close species from subgenus Chrooxantha, group mniszechi (Holynski, 2009).

Key words: Chrysochrod; Chrooxantha; Buprestidae; new subspecies; Myanmar.

\section{Introduction}

Specimens of genus Chrysochroa (Figs 1-5) are found on vast territories through India to Japan at East and Indonesia at South. At present 75 species are described within the genus (Holynski, 2009). In accordance with the review of Holynski, subgenus Chrooxanthaincludes 5 species of group mniszechi, namely, C. mniszechi Deyrolle, 1861, C. miribella Obenberger, 1939, C. klapaleki Obenberger, 1924, C. viridisplendens Thery, 1890, C. flavolimbata Holinsky, 2009. We restore C. margotana Novak, 1992 within this group and describe a new subspecies C. margotana bankoi. In 1992 G. Novak described C. margotana Novak. In 2009 Holynski in his review of the genus reduced this species to a synonym of $C$. viridisplendens (Holynski, 2009). During the last few years Alexander Banko (Quebec, Canada) has collected a large series of Chrysochroa specimens from Burma which have a range of very stable character features that perfectly fit the description of $C$. margotana (Novak, 1992). These characters show clear distinction from C. viridisplendens Thery and confirm that C. margotana Novak is a good species. On a basis of our study of the new material from Myanmar and its distinction from the type series of C. margotana Novak described from Ubon Ratchatani and Chiang Mai, Thailand, a new subspecies is being described. The new subspecies easily differs from the nominate subspecies by very stable golden-orange coloration of elytra without bluish margins that has never been found in other populations of C. margotana, or C. viridisplendens.

\section{Material and methods}

The authors have used traditional methods of morphological examination. Comparative analysis is made using stereo microscope Zeiss Stemi 2000-C.

\footnotetext{
Abbreviations

The following abbreviations are used to locate the storage of paratype specimens:

AT - the private collection of Andrey Yu. Titarenko (Moscow, Russia)

NMPC - National Museum of Czech Republic (Prague, Czech republic)

$A B$ - the private collection of Alexander Banko (Quebec, Canada)
} 

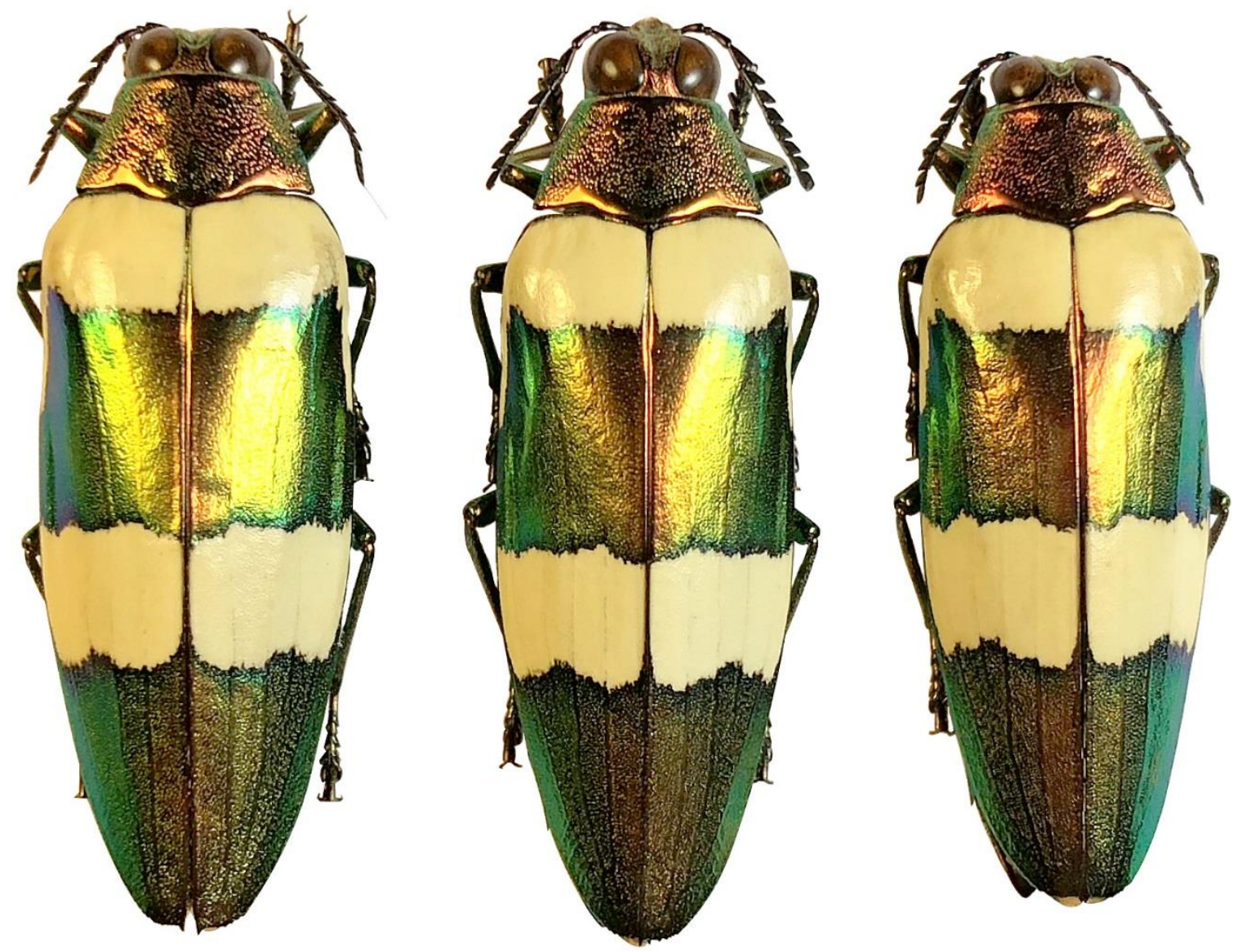

Fig.1. C. margotana bankoi. Holotype and Paratypes. Myanmar
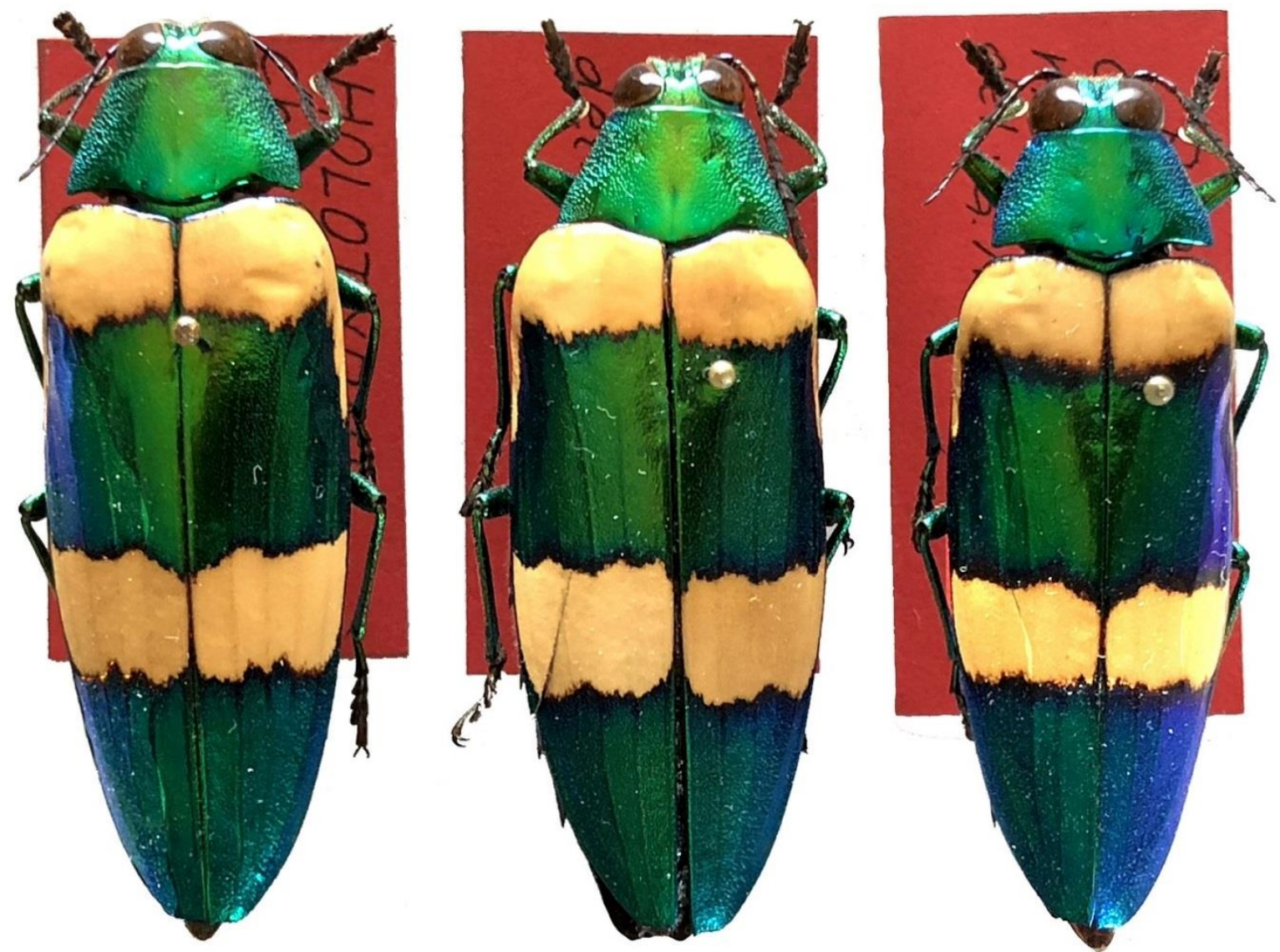

Fig.2. C. margotana margotana. Holotype and Paratypes. Holotype: Thailand, Ubon Ratchatani (NMPC). Allotype, Paratype: Thailand Chiang Mai. Exp. Lehmann 1987 (AT) 

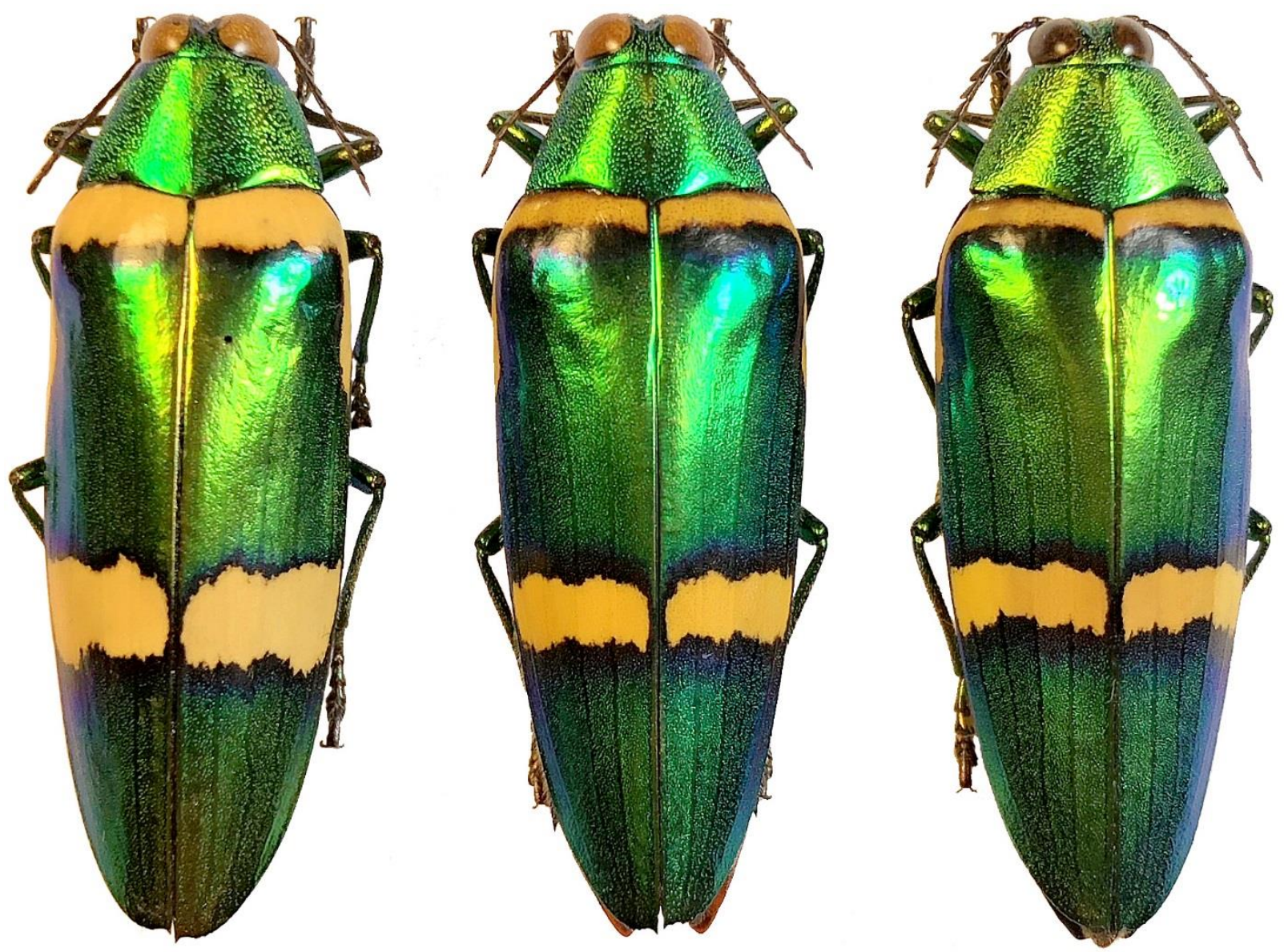

Fig.3. C. viridisplendens. 1 male, S. Vietnam, Kat Thien Nat. Park, 05.2009 (AT), 1 male, 1 female, S. Vietnam, Phan Thiet, Mui Ne, 10.2017 (AT)
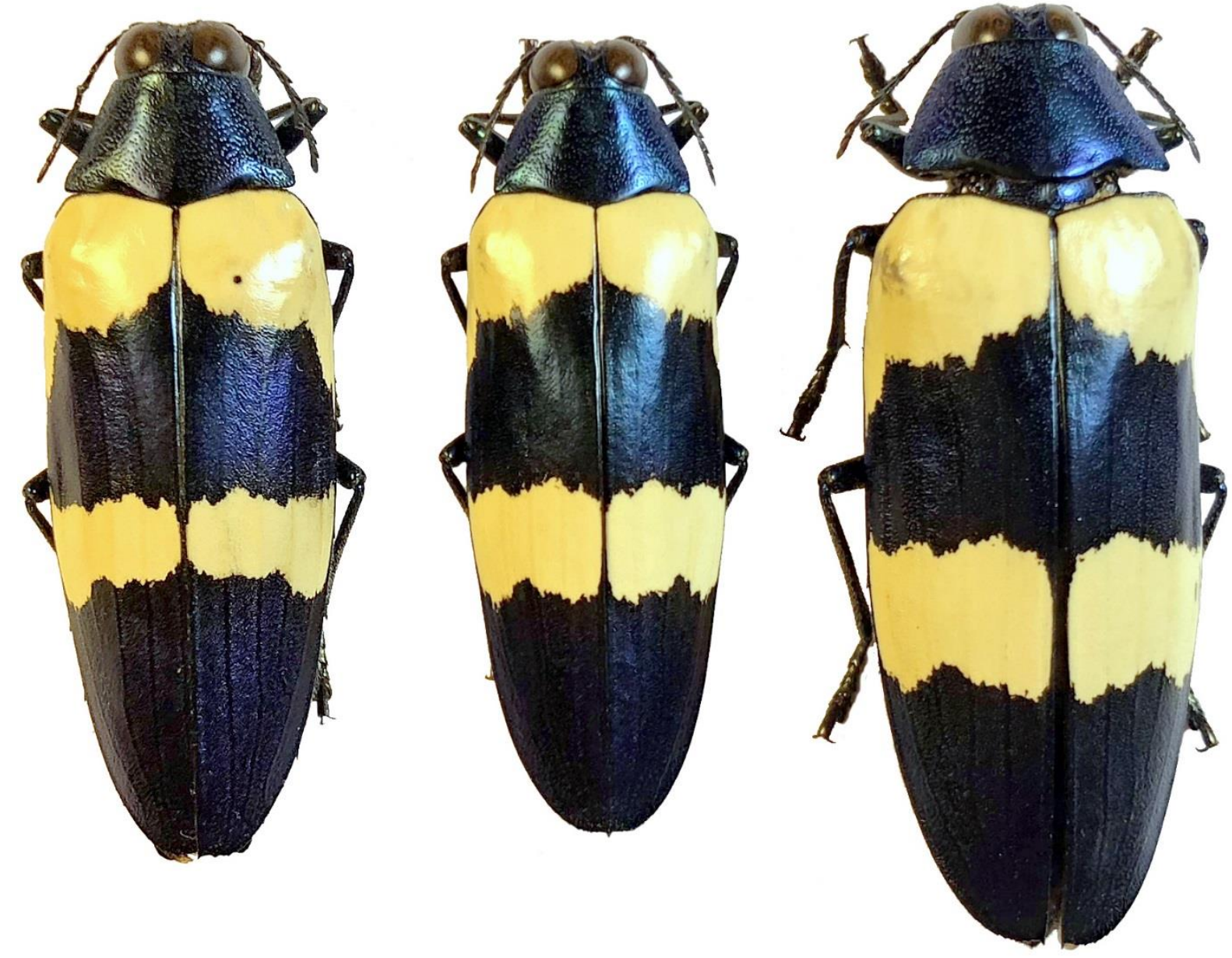

Fig.4. C. mniszechi. Thailand, Maetha, 05. 2017 (AT) 

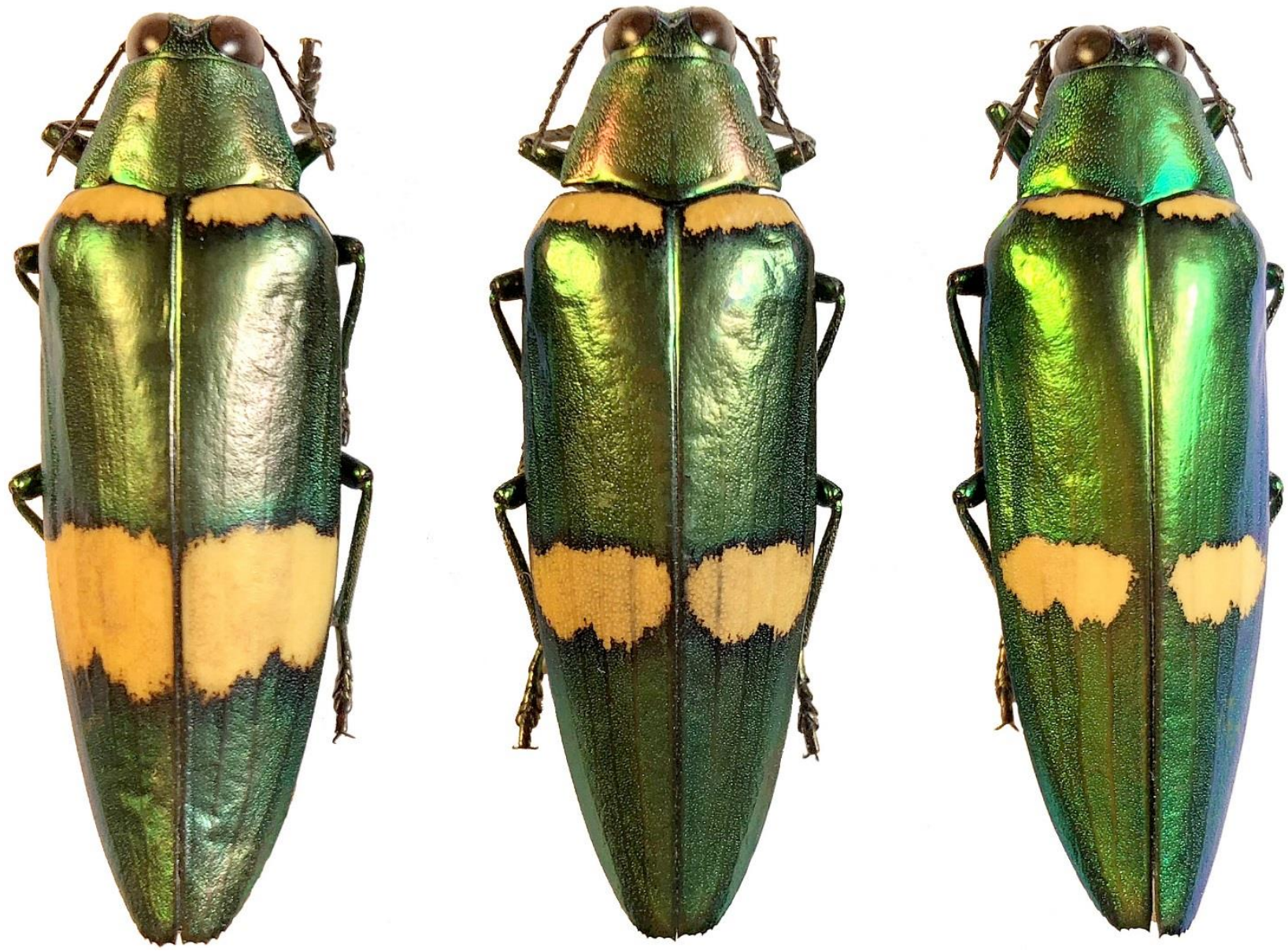

Fig.5. C. klapaleki. N. Kalimantan, Malinau. 05.2017 (AT)

\section{Results}

Chrysochroa (Chrooxantha) margotana Novak, 1992, stat. ressur.

\section{Comparative analysis}

C. margotana was described by G. Novak in 1992 by reference to holotype and two paratype specimens from North Thailand. In 2009 the species name was placed by Holinsky into synonyms of C. viridisplendens, noting that "[e]xamination of the types of C. margotana Nov. has not revealed any character clearly exceeding the range of individual variability of $C$. viridisplendens Thy." (Holynski, 2009). However, this is not correct. The Myanmar population confirms remarkable stability of characters that are described in G. Novak's paper (Novak, 1992).

The distance between the eyes of C. margotana Novak, 1992 (Fig. 2) is wider than in C. mniszechi and C. viridisplendens, however it is distinctly narrower than the eye distance in C. klapaleki (Fig. 6-9).

The impression between eyes of C. margotana Novak, 1992 is wide but not as deep as in C. mniszechi. It has the distinctive shape, thin at the base and wide at the apex. The impression found in specimens of $C$. viridisplendens is narrower but deeper than in C. margotana Novak, 1992. C. klapaleki has the widest impression it occupies almost all the distance between the eyes.

The basal ivory band of C. margotana is wider than in C. viridisplendens and C. klapaleki, however, it is the same wide or slightly narrower than in C. mniszechi Deyrolle, 1861. The hind margin of the basal ivory band of C. margotana is almost straight, while the hind margin of C. mniszechi often expands from the suture to the sides. The hind margin of the basal band of C. margotana, C. mniszechi and C. klapaleki is clear and ragged; such margin of $C$. viridisplendens is diffuse and smooth. The basal band elongates along the margin of elytra. The elongation is the widest in C. mniszechi, and it is narrower in C. margotana and C. viridisplendens. The elongation of $C$. viridisplendens is longer than in C. margotana and C. mniszechi. Such elongation of C. klapaleki is short and weak.

The apical ivory band of C. margotana is wide, close to that of C. mniszechi; it is approximately two times wider than in C. viridisplendens and three-times wider than in C. klapaleki. 
The sutural denticle of elytra of C. margotana is rather long and wide, in C. mniszechi Deyrolle, 1861 it is shorter and narrower and in C. viridisplendens Thery, 1890 it is slightly narrower, in C. klapaleki it is short and wide (Fig. 10).

The anal sternite of females of C. margotana has a straight cutout; C. mniszechi and C. viridisplendens have slightly concave anal sternite; and in C. klapaleki it has a triangular cutout (Fig.11).

The pronotum punctuation of C. margotana is coarser than in C. mniszechi and C. klapaleki, it's texture in C. margotana is close to that of $C$. viridisplendens but slightly denser.

The $6^{\text {th }}$ tergites of males of $C$. margotana has deep round cutout; in C. mniszechi it has a deep triangular cutout, in C. viridisplendens it is slightly rounded, and C. klapaleki has slightly triangular cutout of the tergites.

The aedeagus of $C$. margotana is long, expanded at the base; in C. mniszechi it is slightly wider, expanded near the middle; in C. viridisplendens it is wider than in C. margotana. The aedeagus of C. mniszechi expands evenly. Aedeagus of $C$. klapaleki is shorter and much wider than in the other species of the group.

The penis of $C$. margotana is thin, elongated and sharp at the apex. In C. mniszechi the penis is slightly wider, short and wide at the apex. C. viridisplendens has a wider penis than in C. margotana and C. mniszechi, elongated and narrowed at the apex.

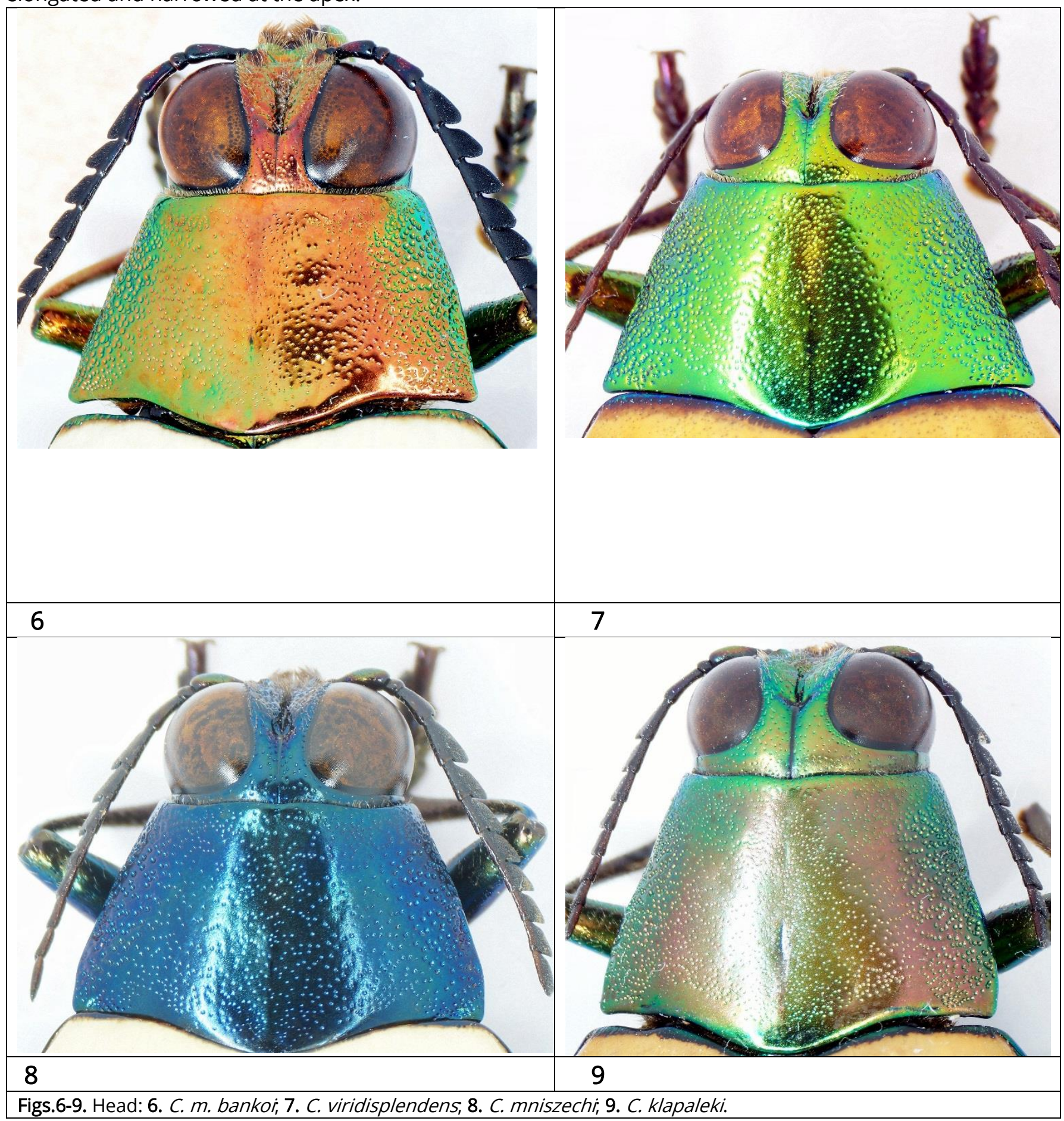



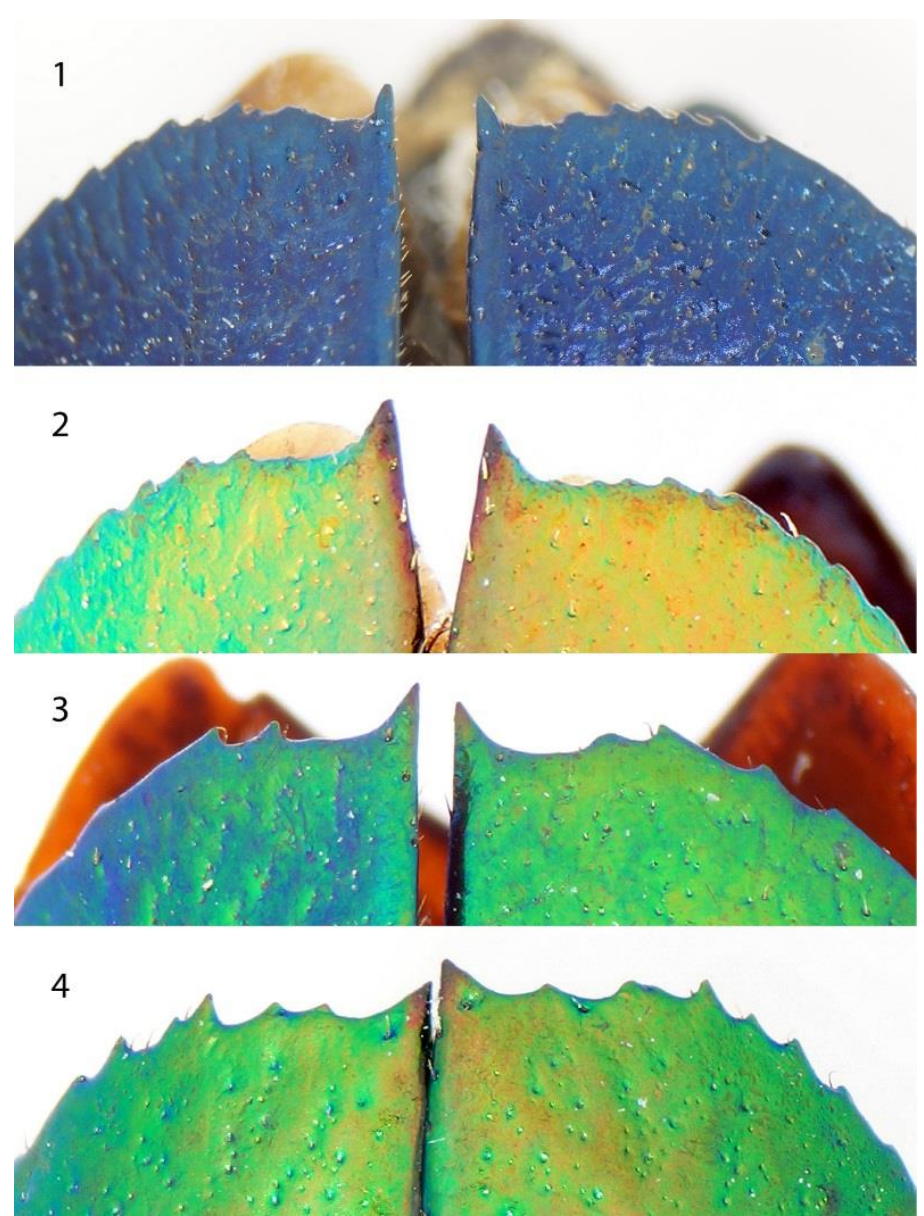

Fig.10. 1-4. Elytra apex. 1. C. mniszechi;2. C. m. bankoi; 3. C. viridisplendens; 4. C. klapaleki.

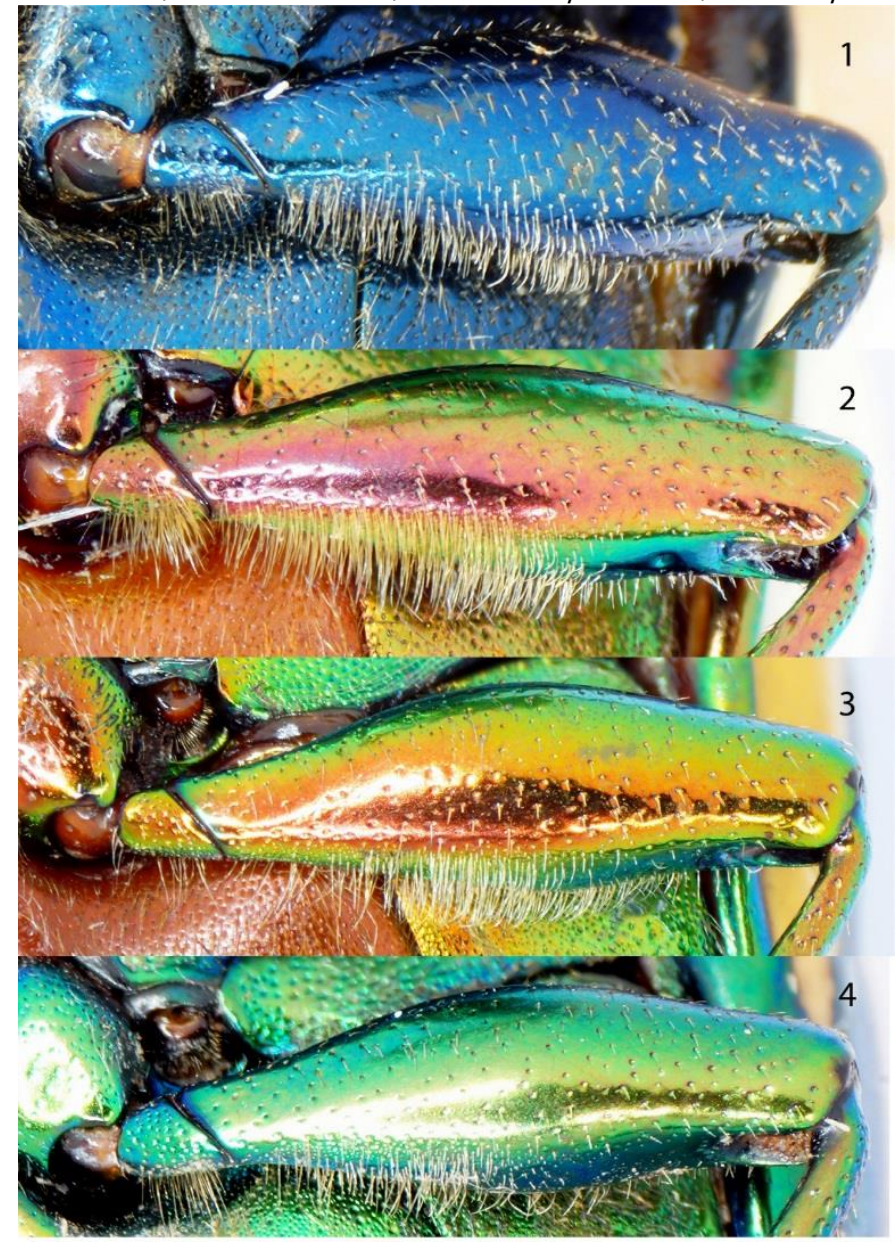

Fig.11. 1-3. Female anal sternite: 1. C. mniszechi;2. C. m. bankoi;3. C. viridisplendens. 

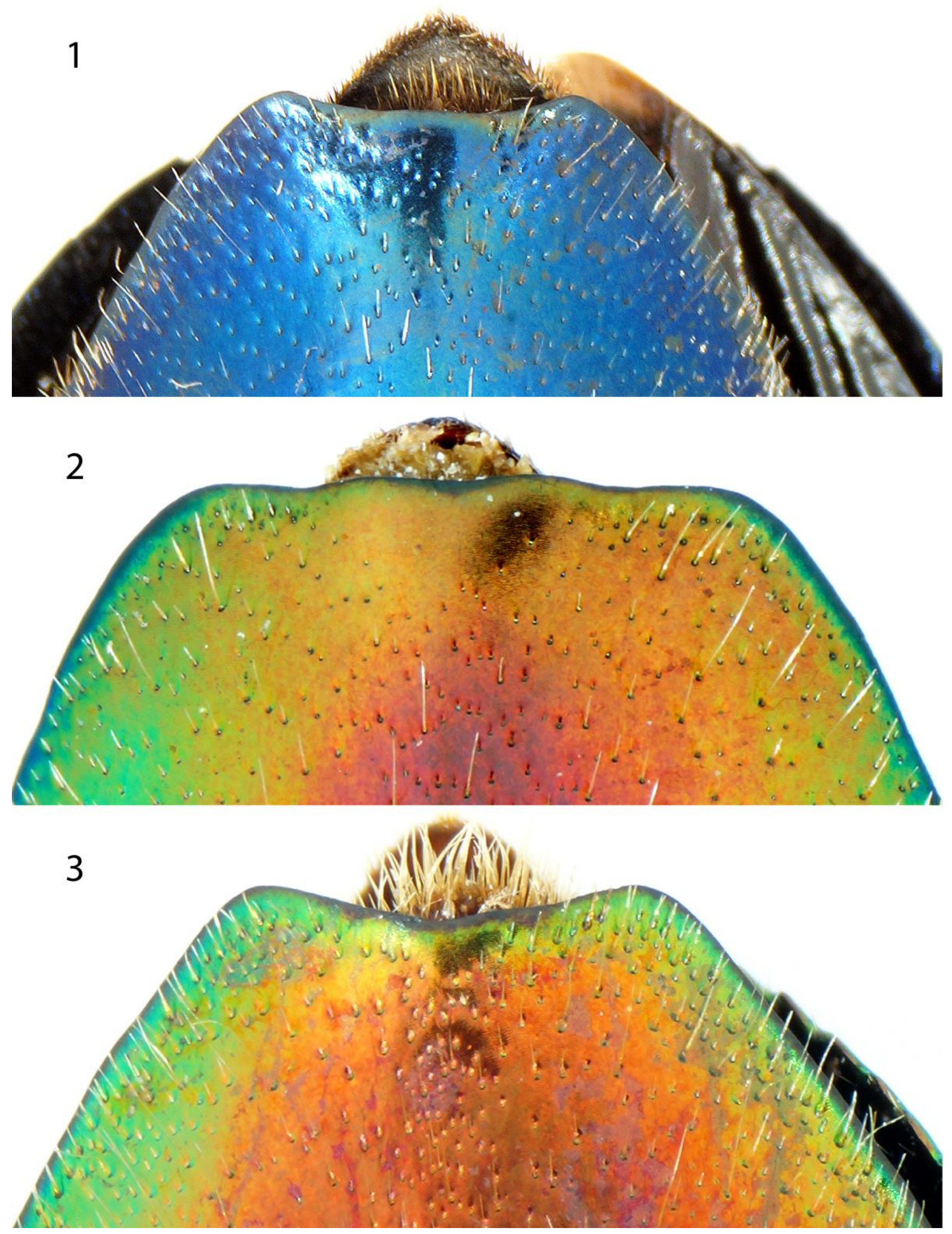

Fig.12. 1-4. Middle femura: 1. C. mniszechi; 2. C. m. bankoi;3. C. viridisplendens; 4. C. klapaleki. 


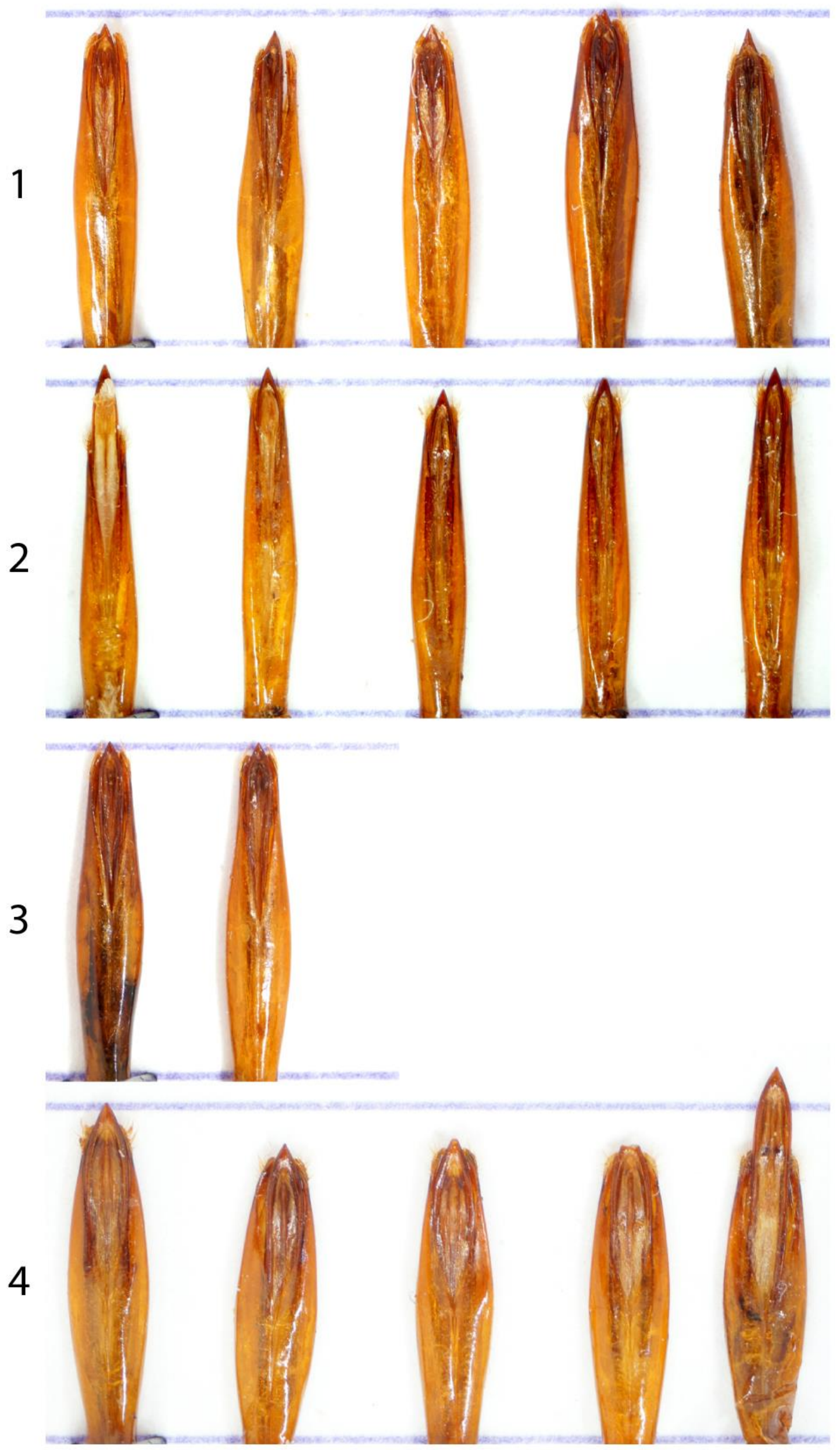

Fig.13. 1-4. Aedeagus: 1. C. viridisplendens; 2. C. m. bankoi; 3. C. mniszechi; 4. C. klapaleki. 


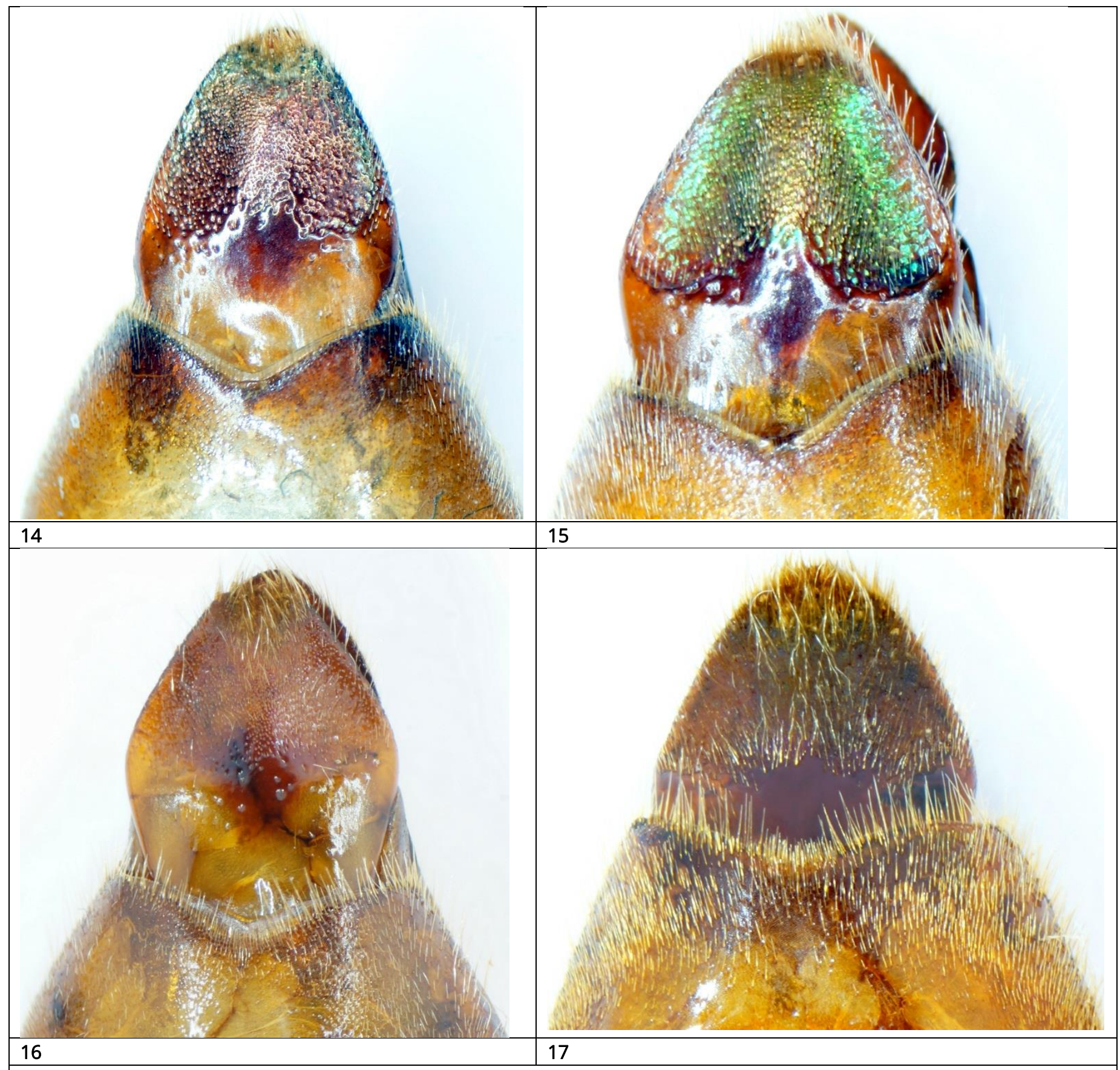

Figs.14-17. Pygidium ventral: 14. C. m. bankoi;15. C. viridisplendens; 16. C. mniszechi;17. C. klapaleki.

\section{Chrysochroa (Chrooxantha) margotana bankoissp.n.}

Type material. Holotype, $\widehat{O}(\mathrm{NMPC})$, Myanmar, 4 km e of Karathuri, h= 350-400m, V-VI.2017 A. Banko leg.,

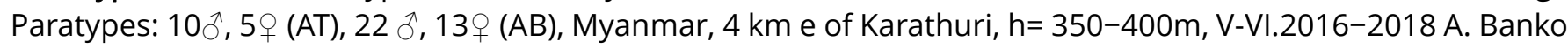
leg.

Description. Body length is $40-47 \mathrm{~mm}$. Holotype $43.5 \mathrm{~mm}$. The abdomen, head, legs, elytra are shiny metallic; the antennae are black. The body, legs, elytra, pronotum and head have golden-orange coloration with strong iridescence to reddish-green. The elytra have two broad ivory bands. The length of the body exceeds its width by three times. The pronotum is short, trapezius, almost 7 times shorter than the full body length. The length of the pronotum is two times shorter than its base. The elytra have rather dense small punctuation, which is slightly rarefied near suture and the base. Each elytron has 4 impunctate costae. The punctuation of the basal ivory band is rare and less even. The elytral apex is rounded with small denticles along the margin and has slightly bigger sutural denticle. The pronotum and the head have rather dense but small-sized punctuation. The $4^{\text {th }}-11^{\text {th }}$ antennae segments are wide, with triangular shape having very small and very dense 
punctuation forming matt surface. The eyes are large and covere almost $70 \%$ of the head. The forehead has a deep impression between eyes. The abdomen has dense short white pubescence. Save for the middle of the sternites, the abdomen coloration can be easily observed. The middle and hind femura are with a brush of short erect white hairs at the rear end; the fore femura have a brush on the front edge. The cutout of the anal sternites of females is straight. The anal sternite of males has triangular cutout. The $6^{\text {th }}$ sternites, pygidium and postpygidium are covered by anal sternites. The cutout of the $6^{\text {th }}$ sternites is triangular. The $6^{\text {th }}$ tegrites has a very small triangular cutout. The pygidium rounded, covered with long adjoined hairs. The Ventral side of pygidium is shiny, with small and very dense punctuation, which is finer at the center. The pygidium punctuation ends near the base. The aedeagus is long and narrow with the pointed apex; it is slightly widened near the base. The parameres have a small brush of long erect hairs at the apex.

\section{Comparative analysis.}

The new subspecies C. margotana bankoi ssp.n has stable golden-orange coloration with iridescence to reddish-green, while the coloration of C. margotana margotana Novak, 1992 is emerald green with iridescence to greenish-blue. The coloration of C. m. margotana is the same as in typical specimens of $C$. viridisplendens. Chrysochroa viridisplendens is emerald green with a hue of blue, sometimes it is completely blue or violet. $C$. $m$. bankoi ssp.n. has no blue, and no blue forms. It is a red species, with a green hue. Each specimen has a green hue at angle, and some specimens are green forms, but average is red. Some red-wine specimens have no green at all. The ivory patch is constant and large and is ivory not yellow. There are no specimens within the Myanmar population which can be considered as having a coloration form which is in a transition path to the emerald-green coloration of C. m. margotana. The absence of such transitional specimens in the Myanmar population proves the validity of the new subspecies name. Pubescence of the hind side of the middle femur of $C . m$. margotana is less dense when in $C . m$. bankoi ssp.n. $C . m$. bankoi ssp.n has slightly smoother ivory bands than in the nominate subspecies. The second ivory band is slightly wider than in C. m. margotana. Further, the Myanmar population is located far from other findings of specimens of nominate subspecies of C. margotana.

Etymology. The new subspecies is named after enthusiastic entomologist Mr. Alexander Banco (Quebec, Canada) who has collected the Myanmar series of this subspecies and found features that differ it from closely related species.

\section{Acknowledgements}

We thank Alexander Banko for his collecting of the type material and preserving it in the excellent quality with the coloration of ivory bands not affected by grease unlike almost all Chrysochroa specimens kept in private and museum collections. We thank Roman B. Holynski (Milanówek, Poland) for providing us with comments on his great comprehensive revision of genus Chrysochroa. We are very grateful to the wife Margo (Vienna, Austria) of the late Mr. Gottfried Novak who made the type series of C. margotana margotana, named after her, available for our study.

\section{References}

Deyrolle, H. (1861). Description de deux Buprestides nouveaux. Annales de la Societe Entomologique de France, (4) 1, 395-396.

Hołyński, R. B. (2009). Taxonomic structure of the subtribe Chrysochroina CAST. with review of the genus Chrysochroa Dej. Warszawa: Gondwana.

Novak, G. (1992). Chrysochroa margotanan. sp., eine weitere Art neben Chrysochroa viridisplendens Thery spec. propr. der Gruppe um Chrysochroa mniszechii Deyrolle (Coleoptera, Buprestidae). Zeitschrift der Arbeitsgemeinschaft Österreichischer Entomologen, 44(3-4), 74-78.

Pisuth Ek-Amnuay. (2008). Beetles of Thailand. Bangkok: Pisuth Ek-Amnuay.

Thery, A. (1898). Description de Buprestides nouveaux et remarques diverses. Annales de la Societe Entomologique de France, 66, 364-369. 


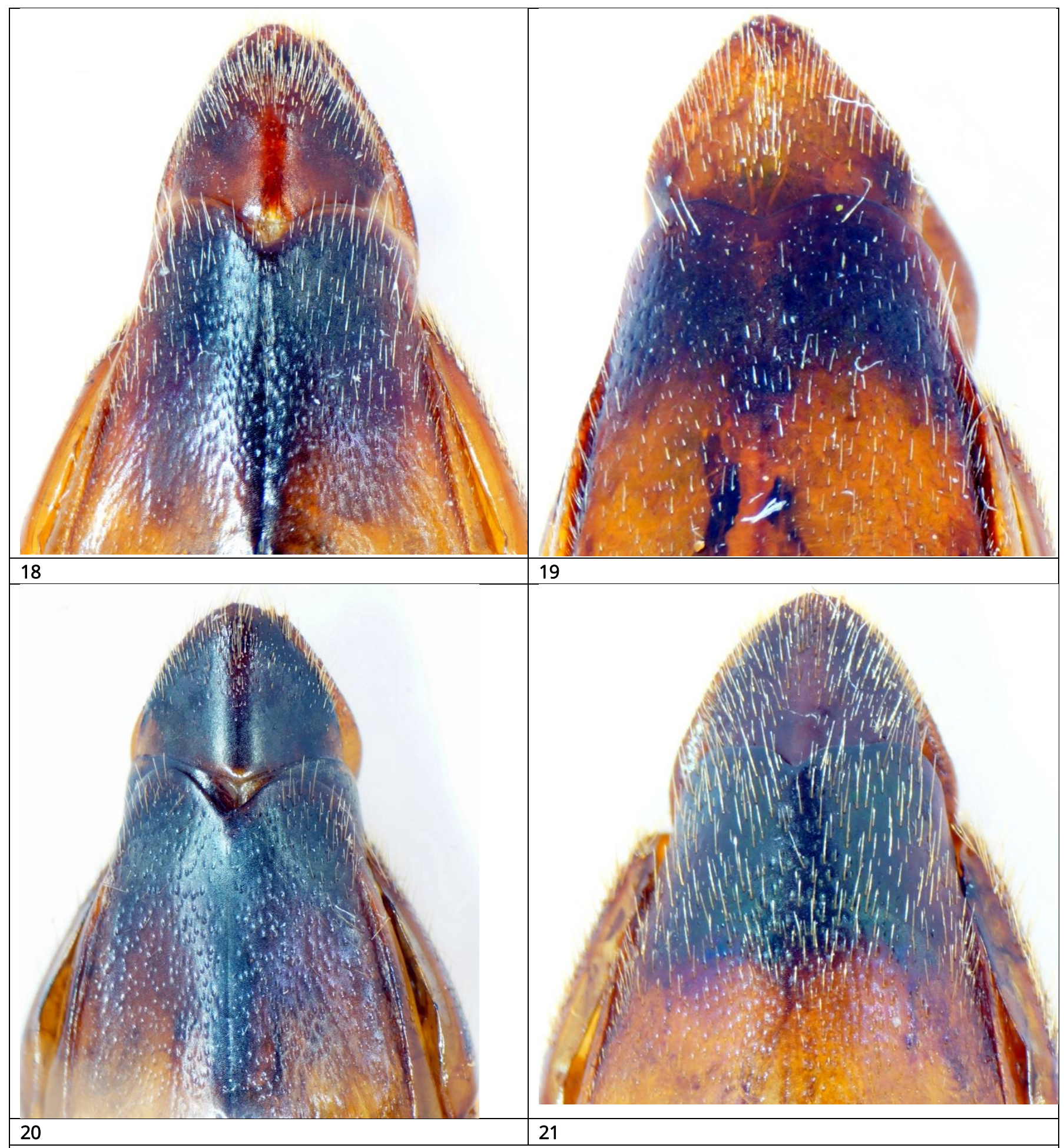

Figs.18-21. Pygidium dorsal. C. m. bankoi;19. C. viridisplendens; 20. C. mniszechi; 21. C. klapaleki. 


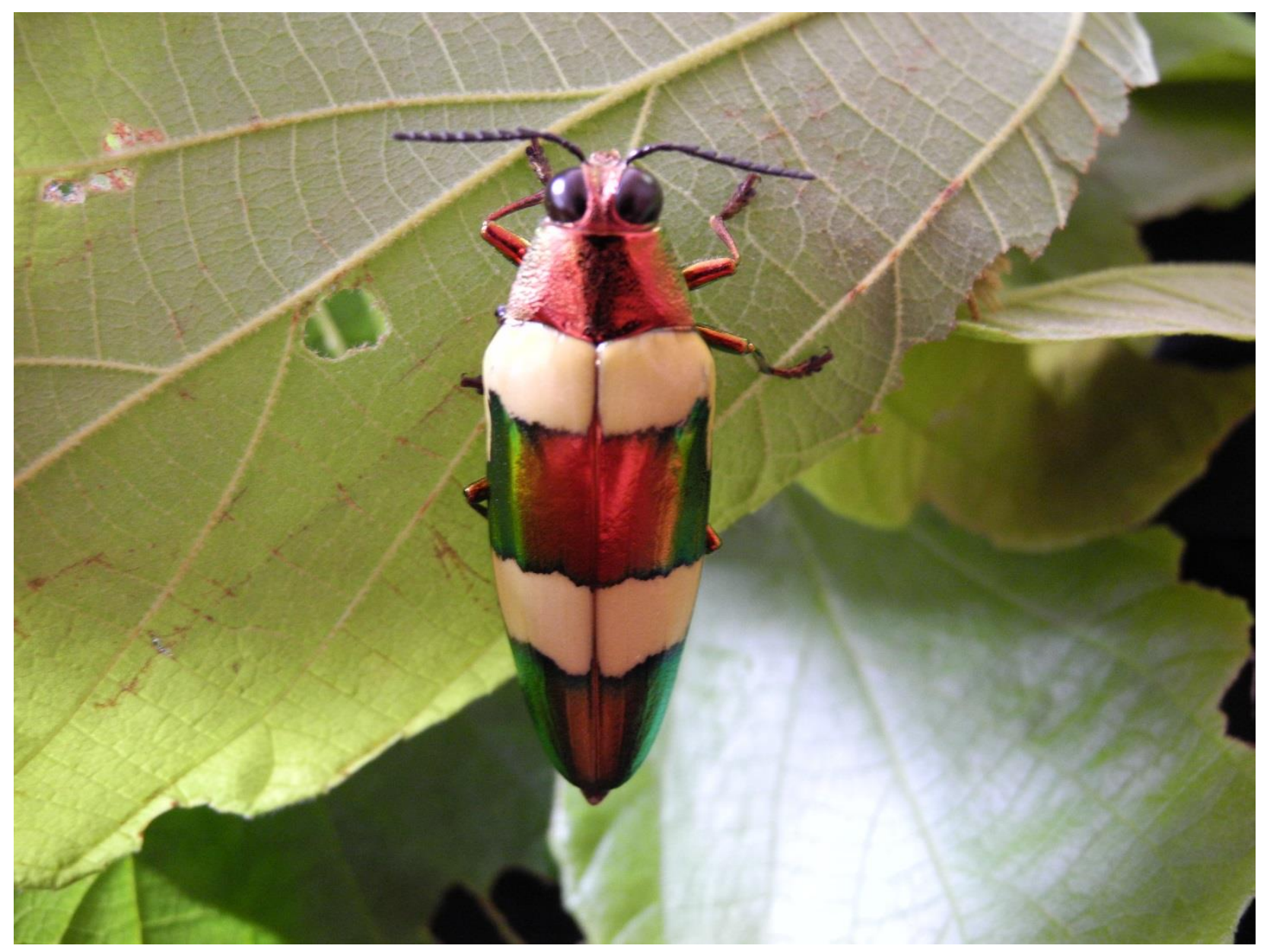

Fig. 22. C. m. bankoi in nature (Photo by A. Banko)

\section{Citation:}

Zubov, A.S., \& Titarenko, A.Yu. (2019). A new subspecies of Chrysochroa margotana Novak, 1992 (Coleoptera, Buprestidae) from Myanmar. Acta Biologica Sibirica, 5 (2), 5-16.

Submitted: 03.01.2019. Accepted: 10.05.2019

cross ref http://dx.doi.org/10.14258/abs.v5.i2.5783

CC (1) 2019 by the authors. Submitted for possible open access publication under the terms and conditions of the Creative Commons Attribution (CC BY) license (http://creativecommons.org/licenses/by/4.0/). 